\title{
Dynamic Simulation of Residential Buildings Supporting the Development of Flexible Control in District Heating Systems
}

\author{
Nadine Aoun ${ }^{1,2,3}$ Roland Bavière ${ }^{2} \quad$ Mathieu Vallée $^{2} \quad$ Adrien Brun $^{2}$ \\ Guillaume Sandou ${ }^{1}$ \\ ${ }^{1}$ L2S, CentraleSupélec, Gif-sur-Yvette, France, \{Nadine.Aoun, Guillaume.Sandou\} @ centralesupelec.fr \\ ${ }^{2}$ CEA, LITEN, Grenoble, France, \{Nadine.Aoun, Roland.Baviere, Mathieu.Vallee, Adrien.Brun $\} @$ cea.fr \\ ${ }^{3}$ ADEME, Angers, France, Nadine.Aoun@ademe.fr
}

\begin{abstract}
Load shifting, peak shaving and night-time setback are key demand-side management measures to make the operation of District Heating Systems (DHSs) more flexible and efficient. These goals can be achieved through appropriate control strategies exploiting the building's and space heating system's thermal inertia. To ease the development of such an advanced controller, we programmed a detailed dynamic Modelica simulator representative of French multi-stories radiator-heated residential buildings. We parametrized the simulator to vary the factors influencing the flexibility potential of a building (e.g. envelope properties, additional internal mass such as partition walls and furniture, the heating system...). This helped us designing a reduced-order building model relevant to our application and setting up a robust identification method for its parameters. We finally used the detailed simulator to test an optimal space-heating controller, thereby allowing many incremental improvements without jeopardizing endusers thermal comfort. This simulation work paves the way to considering the actual implementation of our advanced controller on a real building.
\end{abstract}

Keywords: District Heating System, Optimal Control, Building Simulation, Reduced-order building model

\section{Introduction}

\subsection{Context of this research}

District Heating (DH) has been known for many years as an efficient mode for space heating and domestic hot water preparation in dense urban areas. District Heating Systems (DHSs) have genuinely an important role to play in the future of sustainable energy systems (Lund et al., 2014, 2010) as they allow greater integration of renewable power and recycling of low-temperature excess heat; therefore, a substantial reduction in fossil fuel consumption, $\mathrm{CO}_{2}$ emissions as well as heat production costs can be achieved by converting from individual to district heating. Yet exploiting the full potential of a DHS relies on advanced management at 3 levels: production, distribution and demand. DemandSide Management (DSM) of DHSs is a key measure for peak load shaving. It consists in modulating the heat demand for buildings' space heating by using the available thermal inertia for a free short-term heat storage. Relying on this technology at a city scale, DH production load could be reduced at peak hours thus avoiding the start-up of expensive and pollutant fossil fuel generation units.

Our research group is involved in the design of an optimal space-heating controller for residential buildings connected to DHS. Within the FP7 City-Zen project (City-zen, 2018) we will demonstrate the use of this controller on a building located in the city of Grenoble, France. To support our work during the design and validation phases, we developed a detailed building dynamic simulator. This paper reports on the development of the simulator and its use in the research context we have just described.

\subsection{Structure of this paper}

We organized the remaining part of this paper as follows. Section 2 gives an overview of the programming languages and simulation environments suitable to our application. We then describe the detailed building simulator in section 3. In section 4 we present how we used the simulator to develop and assess an optimal space-heating controller. In section 5, we discuss the obtained results and conclude our study.

\section{Simulation environments}

This part is focusing on building thermal simulation and more broadly on platforms integrating Building Energy Model (BEM). Figure 1 shows examples of applications and related simulation tools. It also indicates an order of magnitude of the number of buildings modelled for each of the applications and the category to which the building model belongs. BEM could be split into two categories, the classic and the simplified.

The classic approach is originally designed for a stand-alone building: TrnSys, EnergyPlus, Pleiade, IDA-Ice, BuildSysPro, Buildings... The building is broken down into a set of walls and volumes. The geometric description can be very realistic. The main assumptions that are made are the unidirectional conductive transfers, and uniform variables on the air volumes. A detailed description of modelling methods is proposed in (JA Clarke, 2001) and (Bruno Peuportier, 2016). These simulation tools have been the subject of numerous benchmarks (Judkoff and Neymark, 2013), (Brun et al., 2009) and experimental validations. 
The simplified approach generally uses analogy between electricity and heat transfer to represent models as an electrical circuit. This type of modelling assumes a linearization of the long wave radiative transfers and constant heat transfer coefficient. (Foucquier et al., 2013) presents and assess other simplifications that are generally made: merging thermal zones, merging walls and reducing walls discretization. This approach is used in building control-command, energy diagnosis but also when the number of building is important (network control, micro-climate, urban energy flow). There is a wide variety of Resistance-Capacitance (RC) scheme and no dedicated benchmark.

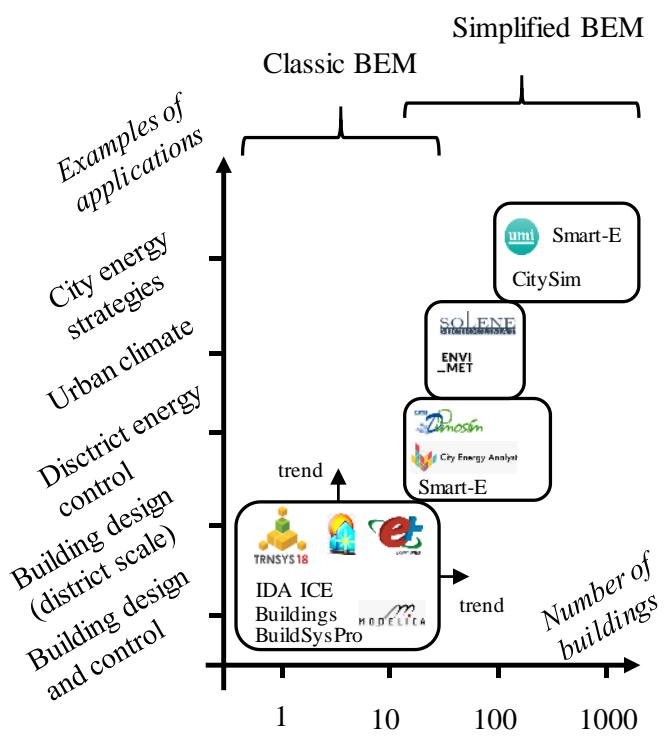

Figure 1. Building simulation environments for various applications and number of buildings.

We can notice that our field of application is the one for which some tools are based on a detailed modelling and others on a simplified modelling. There is currently no consensus on the approach to be used. (Frayssinet et al., 2017) shows that more detail envelope meshing than usual simplified BEM is needed when studying power demand. (Perez et al., 2015) presents the R7C4 monozone model developed to consider the major phenomena in the DIMOSIM simulation platform. In their opinion, classic BEM is not appropriated to simulate a lot of building at the same time due to their high computational time and/or required parameters. (Nageler et al., 2018) presents a study with 34 buildings modelling by means of classic BEM and data driven method. They show that this is technically feasible. (Ribault et al., 2017) showed that Energyplus has interesting feature for decision-support tools for urban densification in a 22 buildings model district. The ease of implementation of distributed computing tends to move the boundary and allow the use of detailed models in large numbers.

In view of the above, we used the Modelica language that allowed us to implement both approaches. A classic
BEM for the building simulator (see section 3) and a simplified approach for the optimal space-heating controller (see section 4.1).

\section{The building simulator}

\subsection{Generalities}

The building simulator is a generic, easily parameterized Modelica model of a multi-storeys building with the main vocation of generating reliable data in replacement of real in-situ measurements. We made some simplifications to obtain representative results while maintaining the parametrization burden tractable. An important design goal of our simulator is the ability to produce numerical results at the expense of reasonable simulation run times.

We built our simulator as a pile of thermally connected identical floors. For simplicity, we considered a rectangular footprint and we discretized each floor into 4 thermal zones, with configurable surface fractions, as shown in Figure 2. The orientation of the building simulator is set using the $\Theta$ azimuth angle between the North direction and the building main axis (see Figure 2). The default value of 0 for $\Theta$ can be used to represent and "ideal" orientation where equivalent Night, Day, Kitchen and Bathroom zones are facing North, South, West and East, respectively.

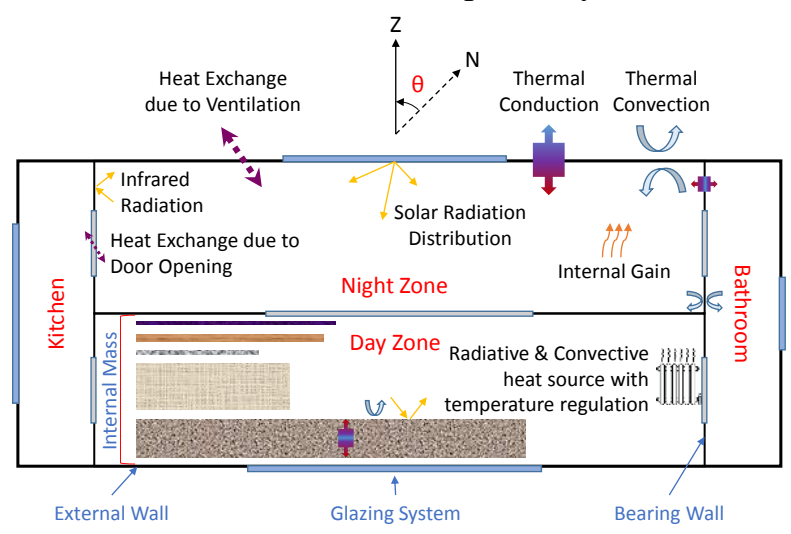

Figure 2. Spatial discretization of one floor (top view) showing the modelled elements and the thermal phenomena considered in the simulator.

We represent each thermal zones using a MixedAir model from the Modelica Buildings library (Wetter et al., 2011). Thus, our simulator considers transient heat conduction through opaque walls, heat transfer through glazed surfaces (with consideration of solar and infrared irradiations), and external/internal convective and radiative heat transfers. Our simulator also includes a hydronic space-heating system composed of a centralized production unit, distribution pipes and radiators each equipped with a thermostatic valve. We used the RadiatorEN442_2 model from the Buildings library and models from our own Modelica DistrictHeating library (Giraud et al., 2015) for the 
distribution pipes, the centralized production unit and the thermostatic valves.

We also implemented a stochastic model of internal gains at the thermal zone level. We statistically model the signal for each zone by combining three heat sources related to occupancy profile, electric appliances and domestic hot water use at a 10 minutes time step. Finally, we expose the simulator to meteorological boundary conditions; we used the ReaderTMY3, a weather file reader from Buildings in which we can upload Typical Meteorological Year (TMY) data for various cities in France and Europe. An interested reader will find further modelling details in the following sections.

\subsection{The envelope and the internal structures}

External walls forming the envelope integrate glazing systems of specific height and width, with neither overhangs nor side-fins. Thermal zones are separated by bearing walls. As for the zones' interior, we carried out the modelling of internal partition walls and furniture with special attention since their mass is potentially a significant contributor to short-term storage. In fact, many studies have found that thermal inertia of building's internal mass has the potential, under certain conditions, to maintain a decent comfort level inside the building for hours after cutting off, or reducing, the heating power (Antonopoulos and Koronaki, 2000; Le Dréau and Heiselberg, 2016; Wolisz et al., 2015). Therefore, empty zones would not reflect the correct dynamics of the building. Furnishing elements and light partition walls are modelled as horizontal and vertical slabs, respectively with the properties listed in Table 1. We referred to (Johra and Heiselberg, 2017), a survey on the internal mass and its equivalent heat capacity found in residential and single office buildings in Denmark, to set these material properties, mass and dimensions of furniture equivalent slabs.

Table 1. Properties of the internal mass equivalent slabs: Thermal conductivity $(\mathrm{k})$, Specific heat capacity $(\mathrm{c})$, Density $(\rho)$, Mass per zone area $(m)$ and thickness $(\varepsilon)$.

\begin{tabular}{|c|c|c|c|c|c|}
\hline $\begin{array}{c}\text { Materia } \\
1\end{array}$ & $\begin{array}{c}\mathbf{k} \\
(\mathbf{W} / \mathbf{m} \cdot \mathbf{K})\end{array}$ & $\begin{array}{c}\mathbf{c} \\
(\mathrm{J} / \mathbf{k g} \cdot \mathbf{K})\end{array}$ & $\begin{array}{c}\rho \\
\left(\mathbf{k g} / \mathbf{m}^{3}\right)\end{array}$ & $\underset{\left(\mathrm{kg} / \mathrm{m}^{2}\right)}{\mathbf{m}}$ & $\begin{array}{c}\boldsymbol{\varepsilon} \\
(\mathbf{m m})\end{array}$ \\
\hline Metal & 60 & 450 & 8000 & 25 & 3 \\
\hline $\begin{array}{l}\text { Wood / } \\
\text { Plastic }\end{array}$ & 0.2 & 1400 & 800 & 25 & 18 \\
\hline $\begin{array}{c}\text { Cerami } \\
\text { c / } \\
\text { Glass }\end{array}$ & 1.25 & 950 & 2000 & 5 & 10 \\
\hline $\begin{array}{c}\text { Light } \\
\text { materia } \\
1\end{array}$ & 0.03 & 1400 & 80 & 15 & 120 \\
\hline $\begin{array}{l}\text { Light } \\
\text { partitio } \\
\text { n walls }\end{array}$ & 0.015 & 1150 & 384 & 25 & 100 \\
\hline
\end{tabular}

\subsection{Thermal phenomena within the zones}

This section details the physical modelling of the considered thermal phenomena, symbolically depicted in Figure 2.
Object-oriented Modelica language allows reusability of pre-developed and validated components. In our simulator, we rely on a thermal zone model, called MixedAir found in the Modelica Buildings library and we use to it model each of the building's zones. MixedAir is a volume of homogenous medium, typically ambiance air, with boundary elements including walls, slabs, windows, floor and ceiling. These construction elements, also found in Buildings library, may be exposed to external meteorological conditions via a weather bus reading a weather file, or boundary conditions of adjacent thermal zones in the case of a shared wall, or the boundary conditions of the same thermal zone in the case of internal partition walls. Under dynamic simulation and due to temperature differences, the volume of air exchanges heat with its surroundings, thus affecting its thermal states and those of the surroundings elements. Here is a concise description of the thermal phenomena that are modelled within MixedAir, further details may be found in (Wetter et al., 2011).

\section{- Convection}

Thermal convection on both sides of each construction element. Two options are available, either using a temperature, flow and tilt dependent convection coefficient or one with a fixed value. In our simulator, we selected a fixed coefficient of $3 \mathrm{~W} / \mathrm{m}^{2}$ for internal convection and $10 \mathrm{~W} / \mathrm{m}^{2}$ for external convection.

\section{- Conduction}

Thermal conduction through multi-layers construction elements is assumed to be mono-directional and computed by solving the heat equation after discretization into a number of states. For each layer, the number of states is proportional to the ratio between the layer thickness and the square root of the material's diffusivity:

$$
n s t a \propto \varepsilon \cdot \sqrt{\frac{c \cdot \rho}{k}}
$$

\section{- Radiation}

MixedAir has a complex model for solar radiation thoroughly described in (Wetter et al., 2011) In short, solar radiation that penetrates the unshaded windows is computed. First it strikes the floor construction where part of it is absorbed and the rest is reflected towards the walls and the ceiling. Surfaces then exchange longwave radiation between each other according to the StephanBoltzmann law which may optionally be linearized. Additionally, other sources of radiation may be injected, for instance radiative heat from internal gain or from a heating system. An interesting output from the radiation model embedded in MixedAir is the room's radiative temperature roughly equal to the average temperature of all the internal surfaces. Note that in our simulator all windows are simulated with no shades for simplicity. 
- Mass transfer

Although MixedAir is designed with a fluid port for explicit modelling of aeraulic flows, in our simulator direct heat transfer to the outdoor environment and between zones respectively due to ventilation and door opening is modelled as follows:

\section{○ Simple-flux ventilation}

$$
\begin{aligned}
\Phi_{\text {zone } \rightarrow \text { outdoor }}= & \rho^{\text {air }} \cdot c_{p}^{\text {air }} \cdot V \cdot n \\
& \cdot\left(T_{\text {outdoor }}-T_{\text {zone }}\right)
\end{aligned}
$$

where $T_{\text {outdoor }}$ and $T_{\text {zone }}$ are the $\rho^{\text {air }}\left(\mathrm{kg} / \mathrm{m}^{3}\right)$ and $c_{p}^{\text {air }}(\mathrm{J} / \mathrm{kg} \cdot \mathrm{K})$ respectively stand for the density and specific heat capacity of air, $V\left(\mathrm{~m}^{3}\right)$ is the air volume of the thermal zone and $n$ is the number of volume changes per second. In reality $n$ is often variable and should be stochastically modelled depending on tenant's behaviour, however in our work we assume it to be constant to a value recommended under European standards. A typical value for $n$ ranges from 0.2 to 0.6 volume changes per hour (ASHRAE Standard, 1989). The default value in the simulator is 0.3 .

\section{$\circ$ Door opening}

$$
\begin{aligned}
\Phi_{i \rightarrow j}=\rho^{\text {air }} \cdot c_{p}^{\text {air }} \cdot S_{\text {Door }} \cdot v_{\text {mix }} \\
\cdot\left(T_{\text {zone }[i]}-T_{\text {zone }[j]}\right)
\end{aligned}
$$

where $S_{D o o r}\left(m^{2}\right)$ is the open area separating two adjacent zones, $v_{m i x}(m: s)$ is an equivalent mixing air velocity through the door opening. The default value for $v_{\text {mix }}$ is $0.13 \mathrm{~m} / \mathrm{s}$ (Van Schijndel et al., 2003).

The MixedAir model can then be subject to external heat flows connected through two ports: one for convective heat and another for radiative heat. External heat sources are typically the heating system and the internal heat gain due to electric appliances and occupancy. The following sections describe how these latter sources have been modelled.

\subsection{The space-heating system}

This section describes the modelling of the heating system. The model is composed of radiators fed by a two-pipe distribution network that connects a centralized production unit, located in the building basement, to the heated rooms.

As already stated in section 3.1 , we used the RadiatorEN442_2 model from Buildings, which includes computation methods inspired by the EN-442 European standard. To favour numerical efficiency, we limited the discretization level to 3 fluid control volumes.

We developed a model of thermostatic valve to control the hydronic flow through each radiator. The first part of the model is a heat capacity exchanging heat with its environment and representing the sensing bulb of the valve. We defined the heat exchange coefficient using a standard correlation valid for natural convection flows around a vertical cylinder. In most practical situations, this leads to an equivalent thermal time constant (defined as the ratio between inertia and the sensing-bulb to environment thermal conductivity) of approximately 10 minutes. The second part of the model relates the position of the valve to the difference between the sensing bulb temperature and the set-point value. Our model fulfils the specifications of the European standards NF EN 215 to regulate the internal air temperature around a specific set point temperature.

We also used pairs of pre-insulated tubes, available in our Modelica DistrictHeating library (Giraud et al., 2015) to model the building's internal space-heating network. These tubes account for the hydraulic head losses and thermal losses occurring in the system. The model also accounts for heat accumulation in the tubes. Figure 3 describes the model we used to represent the centralized production unit of the building's spaceheating system. This unit can represent a substation when the building is connected to a DHS. As can be seen in the figure, the thermal power injected in the system at the substation, hereafter denoted $\Phi_{\text {SST }}$, is controlled by a cascade of two regulators. "Regulator 1" controls the supply temperature denoted $T_{s}$ by adapting $\Phi_{\mathrm{SST}}$. The set-point value for $T_{s}$ is traditionally provided by a heating curve, whose output is noted $T_{H C}, T_{\text {ext }}$ being the external temperature. In our case, the set-point value for $T_{S}$ can be lower than $T_{H C}$; it is then provided by "Regulator 2" which is fed by a set-point value for $\Phi_{\mathrm{SST}}$, denoted $\Phi_{S S T}^{\text {Set point }}$, and an indirect measurement of $\Phi_{\text {SST }}$ built upon the mass flow-rate ( $\dot{m}$ in Figure 3 ), and the supply and return $\left(T_{r}\right.$ in Figure 3$)$ temperatures. The reasons that guided us to design this control strategy are twofold. First, it can be implemented on existing systems and second, its architecture allows shifting between a traditional temperature-driven mode to a more advanced mode where the heating power is planned using a Model Predictive Control (MPC) approach. This aspect is illustrated in section 4 of the present paper.

\subsection{Internal heat gain model}

Each zone in the building simulator receives a direct internal heat gain flux, half of which is assumed to be convective and the other half is radiative. MixedAir handles these heat fluxes and integrates them into the heat balances of the air and the radiative exchange respectively. MixedAir can also handle latent heat gain, yet it is not used in our work for simplification.

The original stochastic internal gain signal, which is then divided into the two mentioned halves, is modelled beforehand, separately by combining three heat sources related to occupancy profile, electric appliances and domestic hot water use. Generating this signal requires a database with information concerning the presence 
schedule of occupants inside the building, and whether or not they are active or not (i.e. sleeping). In both cases, the occupants' presence generates heat due to their metabolism, and furthermore when they are active, their presence triggers the possibility of using electric devices, such as stoves, ovens and laundry equipment. Whereas other appliances are independent of the activity of tenants, such as refrigerators. All appliances dissipate heat as a fraction of their power input and with a certain delay due to their relative thermal inertia. Domestic hot water usage and its temperature level also affect the signal of internal heat gain. Unfortunately, all the data needed to build the internal gain profile is not available for contemporary households in France. Luckily, a survey was carried out in the UK in 2000 and the collected data concerning the occupancy profiles and the electric devices usage is available for the modelling of internal gain signal of our work (Richardson et al., 2010, 2008). We used Markov chains to model a realistic evolution of the signal based on these data. We referred to the work in (Paatero and Lund, 2006; Widén et al., 2009; Yao and Steemers, 2005) for the modelling of the fraction of dissipated heat from the electric appliances and the domestic hot water. The model generates a signal per zone for a year with a 10 minutes step in accordance with the magnitudes found in the French thermal regulation ${ }^{1}$. We then connect the profiles to the building simulator.

\subsection{Parametrization}

The simulator can be parameterized to describe various types of buildings. Yet there is one particular building of interest in our work for the upcoming experimental demonstration of the advanced control strategy; it is a newly built, 8 stories residential building called Le Salammbô, situated in the neighbourhood of Zac Flaubert in Grenoble - France. It has been constructed in accordance with the recommendations of the latest European standards related to buildings thermal consumptions (RT $2012^{2}$ ) and consumes $20 \%$ less than the threshold set by the standards. It is connected to a low-pressure district heating loop and serves as a demonstrator in the European project City-Zen (Cityzen, 2018).

However, according to Tabula ${ }^{3}$, a statistical study of the French residential buildings from a thermal point of view, Le Salammbô (constructed in 2016) is not representative of buildings of its category (multifamily house) in France (see Figure 4).

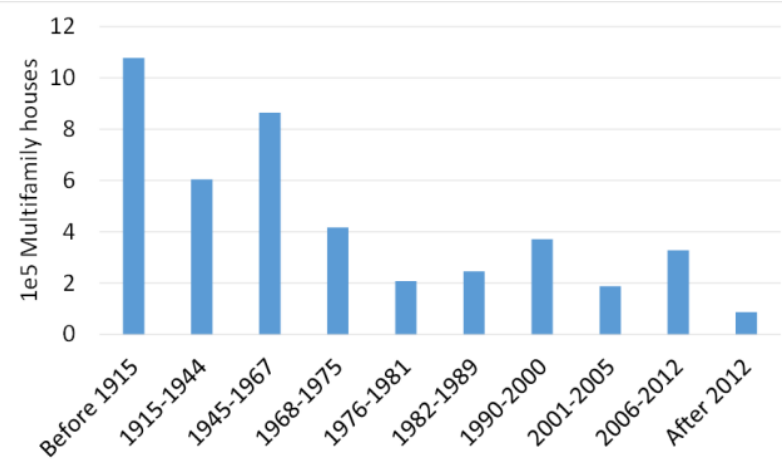

Figure 4. Number of multifamily houses per construction period (Source Tabula ${ }^{3}$ ).

In order to carry out a more inclusive and representative research on advanced control strategies of space-heating demand in DHSs, we decided to parameterize 3 different simulators with the same

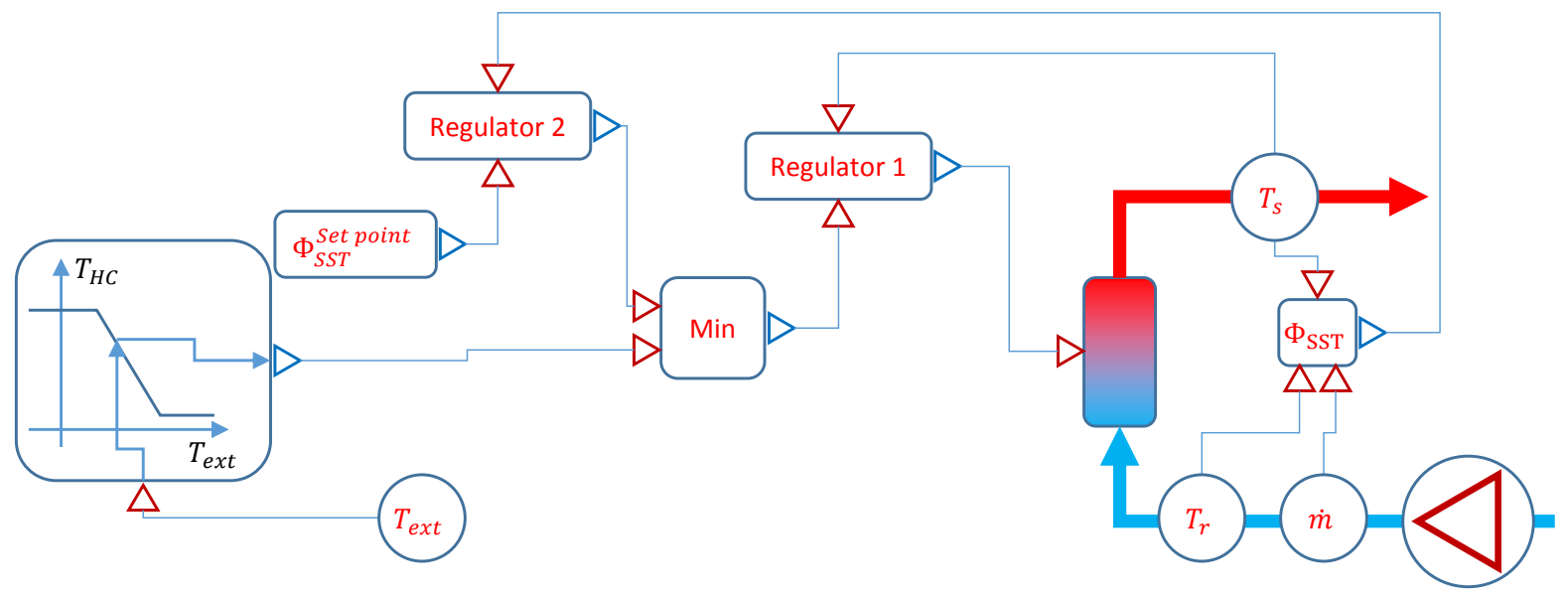

Figure 3. Schematic view of the centralized space-heating production unit composed of hydraulic connections, a circulation pump, the heat generator (right) and the controllers (left).

\footnotetext{
1 Arrêté Du 30 Avril 2013 Portant Approbation de La Méthode de Calcul Th-BCE 2012 Prévue Aux Articles 4, 5 et 6 de L'arrêté Du 26 Octobre 2010 Relatif Aux Caractéristiques Thermiques et Aux Exigences de Performance Énergétique Des Bâtiments Nouveaux et Des Parties Nouvelles de Bâtiments. Annexe Détaillant La Méthode de Calcul ThBCE 2012. 2017
} 2 http://www.gbpn.org/databases-tools/bc-detail-
pages/france\#General\%20Information
3 http://episcope.eu/fileadmin/tabula/public/docs/brochure/FR_TABULA
_TypologyBrochure_Pouget.pdf 
geometric parameters as Le Salammbô but with different construction materials found in Tabula ${ }^{3}$ representing:

A recent building constructed after 2012 because it is representative of Le Salammbô itself.

A building constructed between 1976 and 1981; this category is thermally interesting because it comes just after the year where the first European standards concerning buildings thermal performance (RT 1974) have been introduced.

A building constructed before 1915, since it is the most commonly found in France.

Table 2. Main thermal characteristics for 3 building simulators.

\begin{tabular}{|c|c|c|c|c|}
\hline Simulator & Envelope & $\begin{array}{c}\text { Glazing } \\
\text { system }\end{array}$ & $\begin{array}{l}\text { Number } \\
\text { of air } \\
\text { renewal } \\
\text { per } \\
\text { hour }\end{array}$ & $\begin{array}{c}\text { Sizing } \\
\text { heating } \\
\text { power } \\
(\mathrm{kW})\end{array}$ \\
\hline After 2012 & $\begin{array}{l}\text { Concrete, } \\
\text { exteriorly } \\
\text { insulated with } \\
16 \mathrm{~cm} \text { of } \\
\text { expanded } \\
\text { polystyrene }\end{array}$ & $\begin{array}{l}\text { double- } \\
\text { glazed } \\
\text { with } 16 \\
\mathrm{~cm} \text { of } \\
\text { argon }\end{array}$ & 0.3 & 56.2 \\
\hline $\begin{array}{c}\text { Between } \\
1976 \text { and } \\
1981\end{array}$ & $\begin{array}{l}\text { Cinderblock, } \\
\text { exteriorly } \\
\text { insulated with } 4 \\
\text { cm of expanded } \\
\text { polystyrene }\end{array}$ & $\begin{array}{l}\text { double- } \\
\text { glazed } \\
\text { with } 6 \\
\mathrm{~cm} \text { of air }\end{array}$ & 0.4 & 88.6 \\
\hline $\begin{array}{c}\text { Before } \\
1915\end{array}$ & $\begin{array}{l}\text { Stone }\left(40 \mathrm{~cm}^{-}\right. \\
\text {thick), } \\
\text { uninsulated }\end{array}$ & $\begin{array}{l}\text { single- } \\
\text { glazed }\end{array}$ & 0.5 & 134.8 \\
\hline
\end{tabular}

The main thermal characteristics of the simulators are reported in Table 2. Note that the sizing power is estimated as the building's thermal losses under extreme conditions of $-11^{\circ} \mathrm{C}$ external temperature (the sizing temperature used in the city of Grenoble) with no solar radiations of internal heat gain.

\subsection{Numerical performance}

In this section, we report on the numerical performance of the simulator. We monitored the numerical efficiency of a 8 stroreys building simulator, amounting 32 thermal zones and radiators. The corresponding computational problem weighs $79 k$ non-trivial equations. We translated the model using DYMOLA 2019, compiled it with Microsoft visual C++ build tools 2015, and executed it on a Dell Power Edge $R 640$ server, operated by Windows Server 2016 equipped with two Intel Xeon Gold $61543 \mathrm{GHz}$ processors of 18 cores each. For numerical efficiency reasons, we disabled multithreading. We also decided to enable the Node Interleaving option thereby configuring the server as a Symmetric Shared Memory Multiprocessing (SMP) computer. These settings where found to be optimal for the parallel execution of a simple "for" loop with reduction using OpenMP.

Our test consists in executing simulation runs using various solvers and computing options. The simulations are run for typical winter meteorological conditions. The execution time is expressed under the form of an acceleration factor $A c c_{f}$ defined as the ratio between the simulated period to the execution time. Thus, $A c c_{f}=168$ means that a simulation covering a period of 1 week lasts 1 hour since a week is composed of 168 hours. We limited the maximal time step used by the integrator to $900 s$ by generating time events.

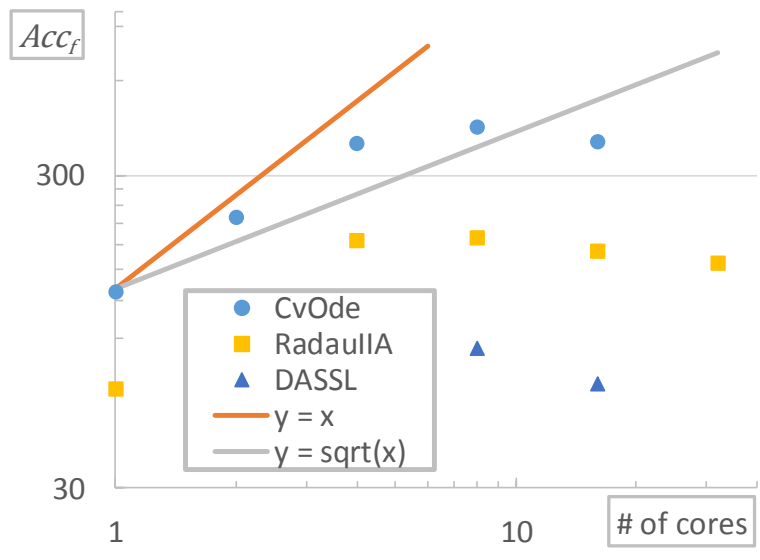

Figure 5. Execution time, expressed as an acceleration factor with respect to real time, as a function of the number of cores and type of solver for a 8 storeys building simulator.

Figure 5 presents the obtained results. The simulation runs are generally shorter when the number of cores used for the calculation increases. Figure 5 shows a quasi-linear trend when the number of cores involved in the calculation is low. However, above 8 cores, there are no more benefits in parallelization. A second observation is that when appropriate solver settings are used, the model execution time can reach $A c c_{f}=420$. Such execution speed is well suited for control applications implying simulation periods in the day to week range. A reduction in the number of thermal zones and/or number of storeys would be necessary to perform annual simulations.

\section{Using the simulator to assess an optimal space-heating controller}

In this section, we describe how we used the simulator to design and test an optimal space heating controller enabling load shedding for DH network. More specifically, we used the simulator to perform three essential steps:

1. Designing a reduced-order building model relevant to our application (section 4.1)

2. Setting up a robust identification method for this model (section 4.2)

3. Validating the obtained optimal space-heating controller, within our simulation tool Pegase (section 4.3) 
One important aspect to underline is that a key issue in the context of our application is the need to perform the building model identification as well as the optimal control with very limited measurements inside the building itself. In particular, optimal space heating control would be very beneficial to $\mathrm{DH}$ operators, however they typically have no access to detailed information or measurements inside the building they are heating. In this context, the detailed and versatile building simulator described in the previous section 3 provided a perfect environment for validating the proposed strategy on a range of different buildings, so that to ensure its reproducibility using real-world data.

\subsection{Reduced-order building model design}

A first step in the proposed optimal control approach is the design of a reduced-order building model (ROM). In our case, we are specifically considering linear or linearsaturated models, which are suitable for a mixed-integer linear programming (MILP) optimization. Although various optimization techniques could be used to perform optimal control, the MILP formulation provides many advantages (proven optimality, short resolution times, easy deployment). It was also shown in previous works that these advantages greatly compensate for the small loss of precision compared to more detailed nonlinear models (Ommen et al., 2014; Schütz et al., 2017).

Simple building modelling is a well-researched topic (see section 2). RC modelling starts by defining the structure of the ROM; i.e. the number of elements we wish to represent for a belief that they might have a considerable influence in the desired application. The simulator comes in handy to test the influence of certain elements. In this section, a parametric study performed using the simulator and which has helped setting the ROM structure is described.

We shall first recall that the ROM will be used to apply and assess DSM measures. For instance, during load shifting, we want to rely on this model to optimally plan the heat delivered to the building without jeopardizing the thermal comfort. We expect the real building inertia to delay the mean internal temperature drop, thus offering heat demand flexibility. Therefore, a reliable ROM structure should well predict these delays. In simplified RC models, thermal delays are created by introducing thermal capacitances (C). The simulator will help us determine, per building class, which element in the building is worth being represented by a "C" in the RC model for MPC applications.

To answer this question we considered the 3 building simulators already presented in section 3.6 and Table 2 . For each of these buildings we considered 3 levels of internal mass by simply modifying the parameter of the mass density per $\mathrm{m}^{2}$ of furniture-equivalent slabs:

Empty zones with no internal mass.

Light internal mass of a total of $70 \mathrm{~kg} / \mathrm{m}^{2}$.

Heavy internal mass of a total of $140 \mathrm{~kg} / \mathrm{m}^{2}$.
For each case we considered 3 simulations to assess the influence of the heating circuit inertia:

A simulation where the heating system model is omitted and heat is directly injected into the zones through the internal air node.

A simulation with low temperature radiator system having a supply water at $50^{\circ} \mathrm{C}$

A simulation with high temperature radiator system having a supply water at $70^{\circ} \mathrm{C}$

Using the thus derived versions of the simulator, we could record the effect of shutting down the heating power to characterize the building time constants, using the following simulation protocol:

1. Reaching steady state conditions, for an internal temperature set-point of $20^{\circ} \mathrm{C}$.

2. Cutting out the power supply at the substation.

3. Recording the internal temperature drop, up to a $1^{\circ} \mathrm{C}$ drop from the set point.

4. Comparing the time constants sensibility obtained for each insulation class to the addition of internal mass and the heating system's inertia.

From this study we could conclude that taking into account both the space-heating circuit and the internal thermal mass were of prime importance for load shedding for all building classes. The obtained detailed results from the simulator can also be compared to the experimental study in (Kensby et al., 2015), in which conclusions could only be reached about the need for considering several time constants.

Therefore, we propose the structure depicted in Figure 6 for MPC applications. The building model features 3 thermal capacitances, 4 thermal resistances and 3 solar gain coefficients. The building model is linear and can be easily derived from the analogical network. The heating circuit model features 1 thermal capacitance to delay the heat delivered at the substation level $\Phi_{S S T}$ from that injected into the air node $\Phi_{\text {rad }}$. It is symbolically represented in Figure 6. Equations of this model include a saturation to limit the substation power to its maximum sizing value. These aspects are rarely modelled in other studies, but the flexibility of Modelica enabled us to model them and assess their importance in a single tool.

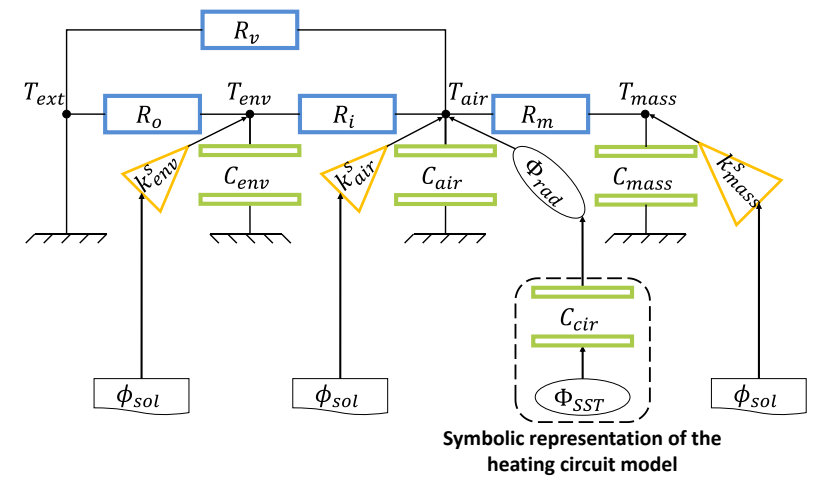

Figure 6. Structure of ROM proposed in light of the parametric study performed using the building simulator. 
Table 3. Nomenclature of the ROM elements.

\begin{tabular}{|c|c|c|c|}
\hline Symbol & Meaning & Subscript & Relative to \\
\hline$T$ & Temperature $[\mathrm{K}]$ & ext & $\begin{array}{l}\text { The external } \\
\text { environment }\end{array}$ \\
\hline$C$ & $\begin{array}{l}\text { Thermal capacitance } \\
{[\mathrm{J} / \mathrm{K}]}\end{array}$ & air & $\begin{array}{l}\text { The building } \\
\text { indoor air }\end{array}$ \\
\hline $\boldsymbol{R}_{v}$ & $\begin{array}{l}\text { Thermal resistance of } \\
\text { ventilation }[\mathrm{K} / \mathrm{W}]\end{array}$ & env & $\begin{array}{l}\text { The building } \\
\text { envelope }\end{array}$ \\
\hline $\boldsymbol{R}_{O}$ & $\begin{array}{l}\text { Thermal resistance } \\
\text { between the envelope } \\
\text { and the outdoors [K/W] }\end{array}$ & mass & $\begin{array}{l}\text { The building } \\
\text { internal mass }\end{array}$ \\
\hline $\boldsymbol{R}_{\boldsymbol{i}}$ & $\begin{array}{l}\text { Thermal resistance } \\
\text { between the indoor air } \\
\text { and the envelope }[\mathrm{K} / \mathrm{W}]\end{array}$ & cir & $\begin{array}{l}\text { The heating } \\
\text { circuit }\end{array}$ \\
\hline $\boldsymbol{R}_{\boldsymbol{m}}$ & $\begin{array}{l}\text { Thermal resistance } \\
\text { between the indoor air } \\
\text { and the internal mass } \\
{[\mathrm{K} / \mathrm{W}]}\end{array}$ & & \\
\hline$k^{s}$ & $\begin{array}{l}\text { Solar gain coefficient } \\
{\left[\mathrm{m}^{2}\right]}\end{array}$ & & \\
\hline$\Phi_{\mathrm{SST}}$ & $\begin{array}{l}\text { Space-heating power at } \\
\text { the substation [W] }\end{array}$ & & \\
\hline$\Phi_{\mathrm{rad}}$ & $\begin{array}{l}\text { Space-heating power at } \\
\text { the radiators [W] }\end{array}$ & & \\
\hline$\phi_{\text {sol }}$ & $\begin{array}{l}\text { Global horizontal solar } \\
\text { radiation flux }\left[\mathrm{W} / \mathrm{m}^{2}\right]\end{array}$ & & \\
\hline
\end{tabular}

\subsection{Reduced-order model identification}

After the structure definition comes the parameters' identification. This step requires historical data to tune the parameters of the ROM (Figure 6, marked in a bold font in Table 3), with the goal of obtaining an optimal set of parameters that best fits that historical data. In our work, historical data is replaced by data generated by the building simulator, and we restrain it to real-world data accessible to DH operators which is mostly found at the substation level, i.e. outside the building. This means we need to identify the parameters based on the spaceheating load power at the substation, and without continuous and intrusive internal temperature measurements.

The detailed building simulator was again of great help for this task, as it enabled us to test several identification methods as well as to verify the results on the internal temperature behaviour (which would not be available in the real world).

The identification method itself is based on the GenOpt optimisation toolkit, and will be described in a future publication. Although more detailed results are out of scope of this paper, we could in particular highlight the following two results:

- The chosen ROM performs better at describing the internal temperature behaviour when identified with only load power at substation, compared to other model structures. Interestingly, most previous work considering identification using internal temperature measurements had different findings, which are not exploitable in our case.

- The correlation between the load power error and the internal temperature error only appears for very low load power errors, meaning that a set of identified parameters may seem to perform correctly when looking at load power error, but may be performing poorly when looking at internal temperature error. A more specific characterization of this result is under study.

\subsection{Validation of an optimal space heating controller}

Based on the previous steps and on other work, we were able to design an optimal space heating controller. The space-heating controller is designed to act at the district heating substation level.

As explained in section 4.1, this controller is based on a MILP problem formulation, as well as on a receding horizon principle. More specifically, it performs the following operations at regular time intervals (here 15 minutes):

1. Collect data available at substation level (esp. load power), as well as weather and energy cost predictions. The hypothesis here is that energy provision costs are variable over the day, either because of renewable energy usage or by taking into account variations in the global network load leading to various generator use.

2. Formulate a MILP optimization problem, aiming especially at controlling the power injected at substation level while minimizing energy provision costs and over/under-heating inside the building. Part of this MILP problem is obtained from the reduced-order building model, which describes the expected thermal behaviour of the building.

3. Solve the MILP optimization problem over the a given horizon (typically $24 \mathrm{~h}$ ), in order to define the optimal trajectory of the control variable (here the power injected at substation level)

4. Apply the obtained set point for the next time interval (here $15 \mathrm{~min}$ ), before performing the optimization again to adjust for prediction changes and real system behaviour.

At the validation step, the obtained set points are not applied to the real building, but instead to the building simulator. This particularly enables us to validate that the internal temperature constraints and thermal comfort are well respected.

We used our optimal control tool called Pegase. Pegase is based on the Functional Bloc Simulation Framework (FBSF, 2018) which provides a very efficient $\mathrm{C}++$ co-simulation master fully compatible with the FMI 2.0 standard. Pegase also embeds MILP formulation capacities based on the Eigen linear algebra library (Eigen, 2018), and is integrated with numerous MILP solvers. Using this tool, each iteration step (problem formulation, resolution and building simulation) is performed in a few seconds on a standard PC, using the GLPK open source solver in this case (GLPK, 2018). A real-world deployment of the controller is also available, in which case the building 
simulator FMU is simply replaced with communication to the real system in place.

Figure 7 presents some first results obtained with the optimal space-heating controller. In Figure 7 , the predictive quantities, the outputs of the controller and the results of the detailed building simulator are respectively plotted with dot-dashed lines, dashed lines, and solid lines. From top to bottom, the first 2 graphs present the evolutions of the external temperature, the total solar irradiation and the energy costs respectively. We then present the planned substation power and the internal building mean temperature. The bottom plot shows the evolutions of the supply and return temperatures of the space-heating system. To enable the comparison with a standard control strategy, we also plotted the supply temperature provided by the buildings' heating curve (see section 3.4).

Figure 7 shows that our controller is able to adapt the substation heating power to the actual heating needs of the building. This leads to a decrease of the supply space-heating temperature when solar gains contribute to space heating. Another interesting feature is that the controller is able to decrease the internal building temperature when energy prices are high thereby demonstrating that the space-heating strategy considers a balance between the energy purchase costs and the end-users' thermal comfort.

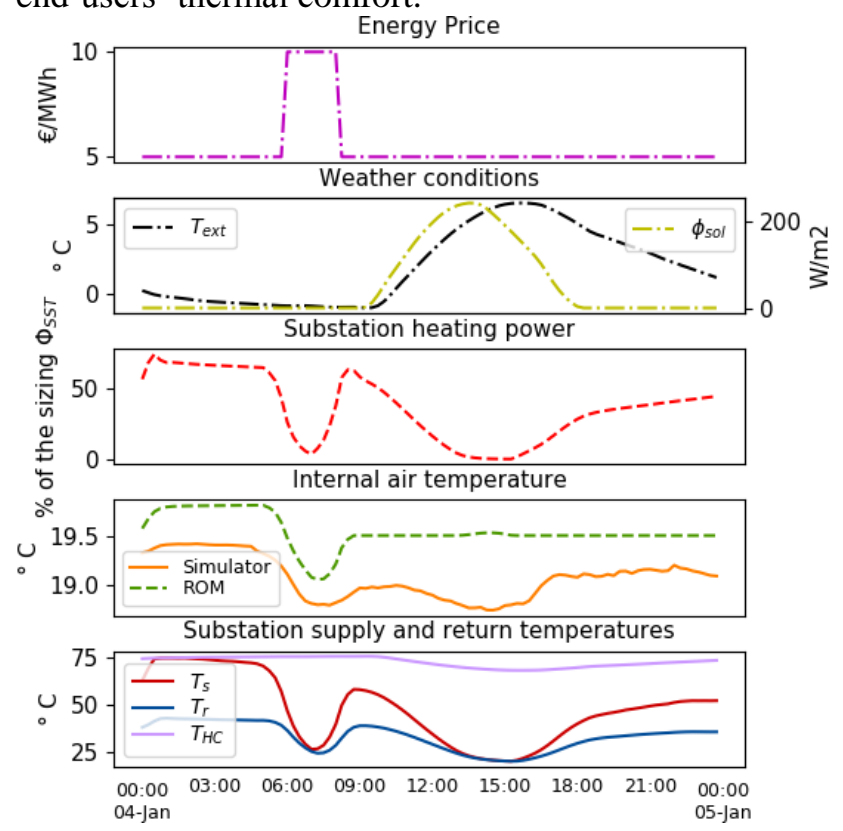

Figure 7. Sample results obtained with the space-heating optimal controller of the model predictive control type.

\section{Conclusion}

In this paper, we present a Modelica-based building simulator and show how it can efficiently support the development of demand-side management control strategies. Based on the MixedAir model available in the Buildings library and on component models developed in the DistrictHeating Library, we designed a customizable simulator for multi-stories radiator-heated residential buildings, representative of the French district heating sector. By using Modelica as a support language, we were able to model not only the building envelope, but also to other relevant elements such as the internal mass and the radiator heating system, which play an important role when considering load shifting.

We also assessed the numerical performance of this building simulator, especially the parallelization features of the Dymola simulation tool. Although the results show some limitation in the parallelization, we could reach an acceleration factor of 420 , meaning that 420 hours can be simulated in 1 hour, in our case using 8 cores in parallel. Such execution speed is well suited for control applications implying simulation periods in the day to week range. A reduction in the number of thermal zones and/or number of storeys would be necessary to perform annual simulations.

Finally, we illustrate how we used the building simulator to design and assess an optimal space-heating controller. In particular, we used the simulator to perform three essential steps: designing a reduced-order building model; setting up a robust identification method for this model; validating the obtained optimal space-heating controller. In all these tasks, being able to define various building models with different parameters, as well as to check the results of the optimal space-heating controller on the simulator were essential.

\section{Acknowledgements}

We gratefully acknowledge ADEME (Agence de l'Environnement et de la Maîtrise de l'Énergie) and the City-Zen project for their support and financial contribution in funding the Ph.D. thesis of Nadine Aoun.

\section{References}

Antonopoulos, K.A., Koronaki, E.P., 2000. Effect of indoor mass on the time constant and thermal delay of buildings. Int. J. Energy Res. 24, 391-402. https://doi.org/10.1002/(SICI)1099114X(200004)24:5<391::AID-ER585>3.0.CO;2-L

ASHRAE Standard: Ventilation for Acceptable Indoor Air Quality, 1989. . American Society of Heating, Refrigerating and Air-Conditioning Engineers, Incorporated.

Brun, A., Spitz, C., Wurtz, E., Mora, L., 2009. Behavioural comparison of some predictive tools used in a lowenergy building, in: Eleventh International IBPSA Conference. pp. 27-30.

Bruno Peuportier, 2016. Energétique des bâtiments et simulation thermique, Eyrolles. ed.

City-zen, 2018. City-zen Project [WWW Document]. Cityzen-Smartcity. URL http://www.cityzensmartcity.eu/

Foucquier, A., Brun, A., Faggianelli, G.A., Suard, F., 2013. Effect of wall merging on a simplified building energy model: accuracy vs number of equations, in: 13th International Building Performance Simulation 
Association (Building Simulation 2013), Chambéry, France, 25-28 August 2013.

Frayssinet, L., Kuznik, F., Hubert, J.-L., Milliez, M., Roux, J.J., 2017. Adaptation of building envelope models for energy simulation at district scale. Energy Procedia, CISBAT 2017 International ConferenceFuture Buildings \& Districts - Energy Efficiency from Nano to Urban Scale 122, 307-312. https://doi.org/10.1016/j.egypro.2017.07.327

Giraud, L., Bavière, R., Vallée, M., Paulus, C., 2015. Presentation, validation and application of the DistrictHeating Modelica library, in: 11th International Modelica Conference. Presented at the 11 th International Modelica Conference, Versailles. JA Clarke, 2001. Energy Simulation in Building Design.

Johra, H., Heiselberg, P., 2017. Influence of internal thermal mass on the indoor thermal dynamics and integration of phase change materials in furniture for building energy storage: A review. Renew. Sustain. Energy Rev. 69, 19-32. https://doi.org/10.1016/j.rser.2016.11.145

Judkoff, R., Neymark, J., 2013. Twenty years on!: updating the IEA BESTEST building thermal fabric test cases for ASHRAE standard 140. Proc. BS2013.

Kensby, J., Trüschel, A., Dalenbäck, J.-O., 2015. Potential of residential buildings as thermal energy storage in district heating systems - Results from a pilot test. Appl. Energy 137, 773-781. https://doi.org/10.1016/j.apenergy.2014.07.026

Le Dréau, J., Heiselberg, P., 2016. Energy flexibility of residential buildings using short term heat storage in the thermal mass. Energy 111, 991-1002. https://doi.org/10.1016/j.energy.2016.05.076

Lund, H., Möller, B., Mathiesen, B.V., Dyrelund, A., 2010. The role of district heating in future renewable energy systems. Energy 35, 1381-1390. https://doi.org/10.1016/j.energy.2009.11.023

Lund, H., Werner, S., Wiltshire, R., Svendsen, S., Thorsen, J.E., Hvelplund, F., Mathiesen, B.V., 2014. 4th Generation District Heating (4GDH). Energy 68, 111. https://doi.org/10.1016/j.energy.2014.02.089

Nageler, P., Koch, A., Mauthner, F., Leusbrock, I., Mach, T., Hochenauer, C., Heimrath, R., 2018. Comparison of dynamic urban building energy models (UBEM): Sigmoid energy signature and physical modelling approach. Energy Build. 179, 333-343. https://doi.org/10.1016/j.enbuild.2018.09.034

Ommen, T., Markussen, W.B., Elmegaard, B., 2014. Comparison of linear, mixed integer and non-linear programming methods in energy system dispatch modelling. Energy 74, 109-118. https://doi.org/10.1016/j.energy.2014.04.023

Paatero, J.V., Lund, P.D., 2006. A model for generating household electricity load profiles. Int. J. Energy Res. 30, 273-290. https://doi.org/10.1002/er.1136

Perez, N., Riederer, P., Inard, C., Partenay, V., 2015. Thermal building modeling adapted to district energy simulation, in: Building Simulation.

Ribault, C., Bouquerel, M., Brun, A., Schumannb, M., Rusaouën, G., Wurtz, E., 2017. Assessing tools relevance for energy simulation at the urban scale: towards decision-support tools for urban design and densification. Energy Procedia, CISBAT 2017 International ConferenceFuture Buildings \&
Districts - Energy Efficiency from Nano to Urban Scale 122, 871-876. https://doi.org/10.1016/j.egypro.2017.07.452

Richardson, I., Thomson, M., Infield, D., 2008. A highresolution domestic building occupancy model for energy demand simulations. Energy Build. 40, 1560-1566. https://doi.org/10.1016/j.enbuild.2008.02.006

Richardson, I., Thomson, M., Infield, D., Clifford, C., 2010. Domestic electricity use: A high-resolution energy demand model. Energy Build. 42, 1878-1887. https://doi.org/10.1016/j.enbuild.2010.05.023

Schütz, T., Schiffer, L., Harb, H., Fuchs, M., Müller, D., 2017. Optimal design of energy conversion units and envelopes for residential building retrofits using a comprehensive MILP model. Appl. Energy 185, 115. https://doi.org/10.1016/j.apenergy.2016.10.049

Van Schijndel, H., Zmeureanu, R., Stathopoulos, T., 2003. Simulation of air infiltration through revolving doors, in: Eighth International IBPSA Conference, Eindhoven, Netherlands.

Wetter, M., Zuo, W., Nouidui, T.S., 2011. Modeling of heat transfer in rooms in the modelica "buildings" library, in: Proceedings of Building Simulation 2011: 12th Conference of International Building Performance Simulation Association. Presented at the 12th Conference of International Building Performance Simulation Association Building Simulation 2011, BS 2011, pp. 1096-1103.

Widén, J., Lundh, M., Vassileva, I., Dahlquist, E., Ellegård, K., Wäckelgård, E., 2009. Constructing load profiles for household electricity and hot water from timeuse data-Modelling approach and validation. $\begin{array}{llll}\text { Energy } & \text { Build. } & \text { 71, }\end{array}$ https://doi.org/10.1016/j.enbuild.2009.02.013

Wolisz, H., Kull, T.M., Streblow, R., Müller, D., 2015. The effect of furniture and floor covering upon dynamic thermal building simulations. Presented at the Energy Procedia, pp. 2154-2159. https://doi.org/10.1016/j.egypro.2015.11.304

Yao, R., Steemers, K., 2005. A method of formulating energy load profile for domestic buildings in the UK. Energy Build. 37, 663-671. https://doi.org/10.1016/j.enbuild.2004.09.007 